\title{
The response of Toll-like receptors to glutamine in neonatal rat intestine
}

\author{
ABDULBAKI KARAOGLU ${ }^{1}$, TURAN TUNC ${ }^{2}$, GOKHAN AYDEMIR ${ }^{3}$, FERHAT CEKMEZ2, \\ MUSTAFA KUL ${ }^{4}$, SECIL AYDINOZ', VURAL KESIK ${ }^{5}$, TANER OZGURTAS ${ }^{6}$, SERDAR UMIT SARICI ${ }^{4}$
}

${ }^{1}$ Department of Pediatrics, Gulhane Military Medical Faculty, Ankara, Turkey

${ }^{2}$ Department of Neonatology, Gulhane Military Medical Faculty, Ankara, Turkey

${ }^{3}$ Haydarpasa Training Hospital, Gulhane Military Medical Faculty, Department of Pediatrics, Istanbul, Turkey

${ }^{4}$ Department of Neonatology, Gulhane Military Medical Faculty, Istanbul, Turkey

5Department of Pediatric Oncology, Gulhane Military Medical Faculty, Ankara, Turkey

${ }^{6}$ Department of Clinical Biochemistry, Gulhane Military Medical Faculty, Ankara, Turkey

\begin{abstract}
Background: There are several barrier systems in the newborn gastrointestinal tract and one of the most important among these are the Toll-like receptors (TLRs). The aim of this study was to examine the effect of glutamine on Toll-like receptors 2 (TLR-2), TLR-4, and TLR-9 levels in the newborn gut.

Material and methods: Rats were randomly assigned to three experimental groups. Group I (control at day 0) $(n=9)$, group II (control at day 10) $(n=9)$ : oral distilled water, group III (study group) $(n=9)$ : oral glutamine $(200 \mathrm{mg} / \mathrm{kg} /$ day $)$. After 10 days, the ileojejunal segment was removed for biochemical analyses of TLR-2, -4 and -9 .

Results: There was a significant difference between groups for the levels of TLRs. The level of TLR-9 was higher in group I than group II and in group III than group II. There was no statistically significant difference between group I and group III in terms of TLR-9 levels. There were no statistically significant differences between groups for the levels of TLR-2 and TLR-4.

Conclusions: Glutamine administration, by increasing the level of TLR-9, may prevent the increase in the level of TLR-4 in newborn rat intestine. Thus, it may play a protective role in the intestine and reduce the susceptibility to necrotizing enterocolitis (NEC), which is associated with the intensity of TLR-4 expression.
\end{abstract}

Key words: Toll-like receptor, glutamine, intestine, newborn rat.

(Centr Eur J Immunol 2012; 37 (4): 298-302)

\section{Introduction}

In the newborn gastrointestinal tract, there are up to $1 \times$ $\times 10^{9}$ bacterial cells/gr of colonic content at the end of the first week of life [1]. Balanced intestinal microflora have a direct impact on maintaining gut homeostasis, such as by processing nutritional factors and by inducing immune responses [2]. Microbiota also provides a continuous source of antigens and toxins capable of activating the host immune system [3, 4]. A dysregulated immune response to bacterial derivate molecules can result in excessive mucosal inflammation [5]. The recognition of microbial antigens by the newborn host may be accomplished through two branches of the immune system: the innate immune system, which consists of cells and their receptors; and the adaptive immune system, which requires prior exposure to antigenic stimuli and the release of antibodies by lymphocytes [6].

Recent work has shed light on the important and exciting role of innate immune receptors of the intestinal epithelium in the development of necrotizing enterocolitis. These receptors, called Toll-like receptors (TLRs), detect unique molecular sequences on bacteria and other potential pathogens [7, 8]. Ten individual TLRs have been identified in humans, termed TLR-1-TLR-10 [9]. Experimental animal data clearly demonstrate that the TLR pathway has a critical role in limiting mucosal injury from enteral toxins by aiding reparative tissue regeneration and promoting clearance of pathogenic bacteria [10-12]. In the newborn infant, mucosal TLR signaling regulates intestinal responses to post-

Correspondence: Abdulbaki Karaoglu, Assistant Professor, Department of Pediatrics, Gulhane Military Medical Faculty, Ankara, Turkey 06018, phone: 903123041889 , fax: 90312304 4381, e-mail: akaraoglu@gata.edu.tr 
natal colonization, aids development of tolerance to commensal bacteria, and interacts with components of breast milk to maintain the integrity of the intestinal barrier [13-15].

In this study, we examined the effect of glutamine, an important precursor for nucleotide synthesis and glutathione for enterocytes, on the expression of TLR-2, TLR-4, and TLR-9 in a rat model of breast-fed infant gut.

\section{Material and methods}

\section{Animal model}

Ethical approval was obtained from the experimental animal ethics committee of the Gulhane Military Faculty of Medicine (Ankara, Turkey). Three time-mated SpragueDawley pregnant rats obtained from the Gulhane Military Medical Faculty Experimental Research Unit were delivered spontaneously. Three groups were allocated from 27 pups as follows: group I (control at day $0, n=9$ ); group II (control at day 10, $n=9$ ); group III (glutamine, $n=9$ ). The rat pups were housed with their mothers in the same cage and maintained at room temperature with a natural day and night cycle with ad libitum access to standard rat chow tap water. Baby rats were randomly selected and marked on postnatal day 1 and divided equally into 3 groups. Group I was sacrificed immediately after birth. Starting from day 1 until day 10 , group II received breast milk and distilled water; group III received breast milk and $200 \mathrm{mg} / \mathrm{kg} /$ day glutamine. Glutamine supplement was available in capsule form (GNC, Pittsburgh, USA), which was dissolved in distilled water and fed to the rat pups through a 24-gauge angiocath with the help of an injector.

\section{Tissue preparation}

Baby rat pups were sacrificed by cervical dislocation. The ileojejunal part of the intestine was removed and washed with $0.9 \% \mathrm{NaCl}$ to remove residual blood, put into tubes, frozen in liquid nitrogen, and stored at $-70^{\circ} \mathrm{C}$ for biochemical analysis immediately after birth from group I and after a 10-day period from group II and III.

\section{Biochemical analysis}

\section{Homogenate preparation}

The frozen tissues were homogenized in phosphate buffer solution ( $\mathrm{pH}$ : 7.4) by means of a homogenizer (Heidolph Diax 900; Heidolph Elektro GmbH, Kelhaim, Germany) on ice. Homogenates were centrifuged at 14,000 rpm at $4^{\circ} \mathrm{C}$ for $10 \mathrm{~min}$. The supernatants were used for the entire assays. The protein content of tissue homogenates was measured by the method of Lowry [16].

Measurements of rat Toll-like receptor 2 (TLR-2), 4 (TLR-4) and 9 (TLR-9)

We used enzyme-linked immunosorbent assay (ELISA) kits according to the manufacturer's instructions (Cusabio
Biotech Co., Ltd., Hubei Province, P.R. China) to determine the tissue TLR-2, TLR-4, and TLR-9 concentrations. In brief, the microtiter plate was pre-coated with an antibody specific to TLR-2, TLR-4, or TLR-9. Standards or samples were added to the appropriate microtiter plate wells with biotin-conjugated antibodies specific for TLR-2, TLR-4, and TLR-9. Subsequently, avidin conjugated to horseradish peroxidase was added to each microplate well and incubated. TMB (3,3',5,5'-tetramethylbenzidine) substrate solution was then added to each well. Only those wells containing TLR-2, -4, and -9, biotin-conjugated antibody and enzyme-conjugated avidin exhibited a change in color. The enzyme-substrate reaction was terminated by the addition of a sulphuric acid solution and the color change measured spectrophotometrically at a wavelength of $450 \pm 2 \mathrm{~nm}$. The concentrations of TLR-2, -4 , and -9 in the samples were then determined by comparing the O.D. of the samples to the standard curves. The intra-assay and inter-assay coefficients of variation for all assays were $<8 \%$ and $<10 \%$, respectively. We measured all samples in duplicate. Tissue TLR-2, TLR-4 and TLR-9 concentrations were expressed as $\mathrm{pg} / \mathrm{mg}$ protein, $\mathrm{ng} / \mathrm{mg}$ protein and $\mathrm{ng} / \mathrm{mg}$ protein, respectively.

\section{Statistical analysis}

SPSS for Windows version 15.0 (SPSS, Chicago, IL) was used for statistical analyses. $P<0.05$ was accepted as indicating a statistically significant difference. A KruskalWallis test was used for testing differences and a MannWhitney $U$-test was used for comparing groups with each other and with the control group to determine the source of the difference among study groups.

\section{Results}

Figure 1 summarizes TLR-2, TLR-4, and TLR-9 levels in homogenates of intestinal tissue taken from all of the groups. There was a significant difference between groups for TLR-9 level $(p<0.05)$. The level of TLR-9 were significantly higher in group I than group II $(p=0.002)$. There was also a significant difference between group II and group III $(p<0.001)$. The levels of TLR-9 were higher in group III than group II. There was no statistically significant difference between group I and group III in terms of TLR-9 level $(p>0.05)$. There was also no significant difference between groups for TLR-2 and TLR-4 levels $(p>0.05)$ (Table 1).

\section{Discussion}

In this study, we evaluated the alteration and the effect of oral glutamine on TLR-2, TLR-4, and TLR-9 levels in newborn rat intestine in the first ten days of postnatal life. There was no significant difference between study and control groups for TLR-2 and TLR-4 levels, whereas TLR-9 


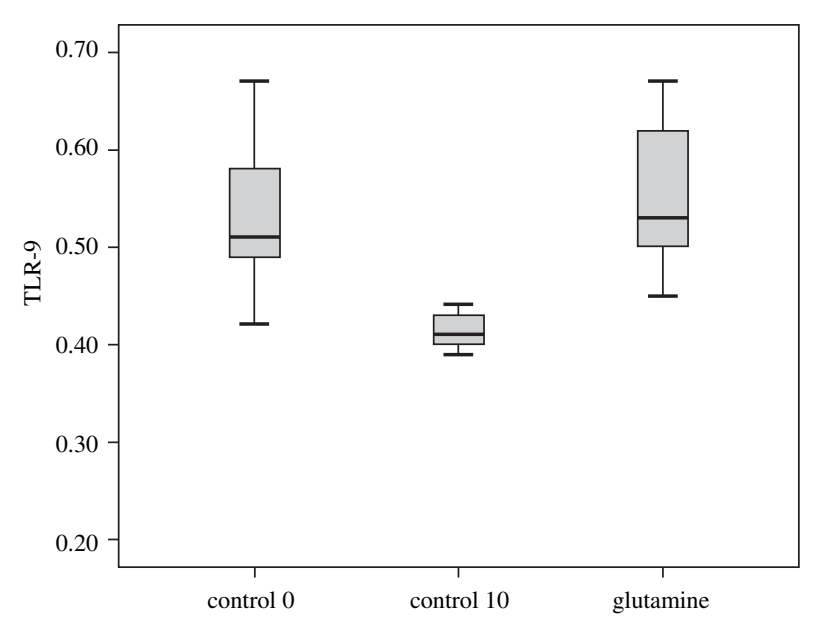

Fig. 1. Toll-like receptor 9 level according to groups

level in group II was significantly lower than group I and III. The level of TLR-9 did not decrease with time and remained high during the study period in group III.

The intestine at birth is thought to be sterile. Bacteria come from the outer environment and intestinal microbiome forms during the neonatal period [17]. Tolerance of the intestinal mucosal immune system may build up through commensal intestinal bacterial stimulation of TLRs [18]. Toll-like receptors are transmembrane components of the innate immune system's pattern recognition receptor family [8]. Intestinal TLRs preserve homeostasis by balancing the proinflammatory and anti-inflammatory immune responses to both commensal and pathogenic microbiota through recognition of bacterial products. The pathogenesis of NEC may arise from the dysregulation of this immune response [19].

The pathophysiology of NEC in premature infants is multifactorial and complex and comprises a history of a complicated early neonatal course, poor intrauterine environment and perinatal transition. The key factors that have been implicated in NEC include intestinal hypoperfusion, abnormal bacterial colonization, a dysregulated immune response, and feeding [20-23].
It has been reported that TLR-4 expression is increased in the intestinal mucosa of mice, rats, and humans with NEC and that this TLR-4 expression in enterocytes may lead to an increase in death of the cells that line the intestine through the process of apoptosis [24-26]. These findings show that TLR-4 expression may lead to the development of intense and harmful effects in promoting intestinal injury and decreasing the ability of mucosal repair in the newborn small intestine.

As we know from previous studies, oral glutamine has many positive effects on the newborn intestine and is implicated in maintaining the functional integrity of the gut [27-29]. Furthermore, it serves as fuel for enterocytes and other proliferating cells, is involved in nucleotide and glutathione synthesis, provides nitrogen for the synthesis of amino sugars, is necessary for the maintenance of tight junctions, and stimulates crypt proliferation in the human ileum [28, 30-32]. Low plasma glutamine concentrations have been reported to be associated with a higher incidence of NEC [33].

Recent evidence has shown that TLR-9, a homologue of TLR-4 and a receptor of bacterial DNA, may prevent exaggerated TLR-4 signaling [7, 34]. Toll-like receptor 9 is the receptor for bacterial DNA rich in CpG groups in enterocytes and in case of activation may lead to a decrease in TLR-4 signaling that is manifested by reduced cytokine production and decreased apoptosis. In fact, these findings may explain the protective effects of probiotics on NEC [34]. That is to say that these probiotics rich in bacterial DNA are expected to reduce TLR-4 signaling and the severity of NEC via activation of TLR-9 [35]. A recently published study has shown that glutamine supplementation had a beneficial effect on intestinal integrity and reduced the incidence of NEC and septicemia [27]. In another experimental study, it was shown that oral glutamine, by reducing TLR-4 expression, may be protective against NEC [36]. In the present study, a significant increase in TLR-9 levels was noticed in the glutamine supplemented group as compared to group II. We propose that oral glutamine supplementation may lead to a reduction in TLR-4 level by increasing TLR-9 level, which may be protective for the preterm gut.

The other aim of this study was to determine whether glutamine has any effect on the TLR-2, and TLR-4 levels,

Table 1. Comparison of the levels of Toll-like receptors between groups

\begin{tabular}{lllll}
\hline Groups & Group I & Group II & Group III & $\boldsymbol{p}$ \\
\hline TLR-2 & 17.28 & 16.70 & 16.52 & NS \\
(pg/mg protein) & $16.04 ; 28.98$ & $11.62 ; 19.39$ & 0.15 & NS \\
TLR-4 & 0.15 & 0.15 & $0.00 ; 0.89$ & 0.53 \\
(ng/mg protein) & $0.00 ; 0.90$ & $0.00 ; 0.88$ & $0.45 ; 0.67$ & $\mathbf{0 . 0 0 2} * \mathbf{0 . 0 5}$ \\
TLR-9 & 0.51 & 0.41 & NS**<0.001*** \\
(ng/mg protein) & $0.42 ; 0.67$ & $0.27 ; 0.50$ & \\
\hline
\end{tabular}

All data are expressed as median, minimum and maximum. $P<0.05$ are considered as significant. $N S-$ not significant, *comparison of group $* 1-2 ; * * 1-3 ; * * * 2-3$ 
the receptors for bacterial ligands associated with gram-positive and gram-negative bacteria, respectively. Toll-like receptor 2 recognizes numerous microbial components of gram-positive bacteria such as peptidoglycan and lipoproteins, despite the fact that TLR-4 is required for lipopolysaccharide responsiveness, which is the outer component of the membrane of gram negative bacteria. Although it has been shown that oral glutamine supplementation has beneficial effects on the newborn intestine, there was no change in TLR-2, and TLR-4 levels during the study period [37-39].

In conclusion, glutamine in the neonatal intestine may play an important and protective role in the pathogenesis of NEC by increasing TLR-9 level in immature preterm intestine via reduction of TLR-4 level. Further studies aimed at evaluating the effects of glutamine on TLRs in a NEC model may shed more light on this issue and contribute to a better understanding of the pathogenesis of NEC.

\section{The authors declare no conflict of interest.}

\section{References}

1. Bezirtzoglou E, Stavropoulou E (2011): Immunology and probiotic impact of the newborn and young children intestinal microflora. Anaerobe 17: 369-374.

2. Husebye E, Hellström PM, Sundler F, et al. (2001): Influence of microbial species on small intestinal myoelectric activity and transit in germ-free rats. Am J Physiol Gastrointest Liver Physiol 280: G368-380.

3. Lin PW, Stoll BJ (2006): Necrotising enterocolitis. Lancet 368: 1271-1283.

4. Wolfs TG, Derikx JP, Hodin CM, et al. (2010): Localization of the lipopolysaccharide recognition complex in the human healthy and inflamed premature and adult gut. Inflamm Bowel Dis 16: 68-75.

5. Xavier RJ, Podolsky DK (2007). Unravelling the pathogenesis of inflammatory bowel disease. Nature 448: 427-434.

6. Iwasaki A, Medzhitov R (2010): Regulation of adaptive immunity by the innate immune system. Science 327: 291-295.

7. Afrazi A, Sodhi CP, Richardson W, et al. (2011): New insights into the pathogenesis and treatment of necrotizing enterocolitis: Toll-like receptors and beyond. Pediatr Res 69: 183-188.

8. Medzhitov R, Preston-Hurlburt P, Janeway CA Jr. (1997): A human homologue of the Drosophila Toll protein signals activation of adaptive immunity. Nature 388: 394-397.

9. Roach JC, Glusman G, Rowen L, et al. (2005): The evolution of vertebrate Toll-like receptors. Proc Natl Acad Sci U S A 102: 9577-9582.

10. Müller CA, Autenrieth IB, Peschel A (2005): Innate defenses of the intestinal epithelial barrier. Cell Mol Life Sci 62: 12971307.

11. Neu J, Chen M, Beierle E (2005): Intestinal innate immunity: how does it relate to the pathogenesis of necrotizing enterocolitis. Semin Pediatr Surg 14: 137-144.

12. Rakoff-Nahoum S, Paglino J, Eslami-Varzaneh F, et al. (2004): Recognition of commensal microflora by toll-like receptors is required for intestinal homeostasis. Cell 118: 229-241.

13. Morowitz MJ, Poroyko V, Caplan M, et al. (2010): Redefining the role of intestinal microbes in the pathogenesis of necrotizing enterocolitis. Pediatrics 125: 777-785.
14. Lotz M, Gütle D, Walther S, et al. (2006): Postnatal acquisition of endotoxin tolerance in intestinal epithelial cells. J Exp Med 203: 973-984.

15. Cario E, Podolsky DK. (2005): Intestinal epithelial TOLLerance versus inTOLLerance of commensals. Mol Immunol 42: 887-893.

16. Lowry OH, Rosebrough NJ, Farr AL, Randall RJ (1951): Protein measurement with the Folin phenol reagent. J Biol Chem 193: 265-275.

17. Adlerberth I, Wold AE (2009): Establishment of the gut microbiota in Western infants. Acta Paediatr 98: 229-238.

18. Zeuthen LH, Fink LN, Frøkiaer H (2008): Toll-like receptor 2 and nucleotide-binding oligomerization domain-2 play divergent roles in the recognition of gut-derived lactobacilli and bifidobacteria in dendritic cells. Immunology 124: 489-502.

19. Abreu MT (2003): Immunologic regulation of toll-like receptors in gut epithelium. Curr Opin Gastroenterol 19: 559-564.

20. Nankervis CA, Giannone PJ, Reber KM (2008): The neonatal intestinal vasculature: contributing factors to necrotizing enterocolitis. Semin Perinatol 32: 83-91.

21. Claud EC, Walker WA (2001): Hypothesis: inappropriate colonization of the premature intestine can cause neonatal necrotizing enterocolitis. FASEB J 15: 1398-1403.

22. Sibbons PD, Spitz L, van Velzen D (1992): Necrotizing enterocolitis induced by local circulatory interruption in the ileum of neonatal piglets. Pediatr Pathol 12: 1-14.

23. Frost BL, Jilling T, Caplan MS (2008): The importance of proinflammatory signaling in neonatal necrotizing enterocolitis. Semin Perinatol 32: 100-106.

24. Leaphart CL, Cavallo J, Gribar SC, et al. (2007): A critical role for TLR4 in the pathogenesis of necrotizing enterocolitis by modulating intestinal injury and repair. J Immunol 179: 4808-4820.

25. Chan KL, Wong KF, Luk JM (2009): Role of LPS/CD14 /TLR4-mediated inflammation in necrotizing enterocolitis: pathogenesis and therapeutic implications. World J Gastroenterol 15: 4745-4752.

26. Richardson WM, Sodhi CP, Russo A, et al. (2010): Nucleotidebinding oligomerization domain-2 inhibits toll-like receptor4 signaling in the intestinal epithelium. Gastroenterology 139: 904-917.

27. Sevastiadou S, Malamitsi-Puchner A, Costalos C, et al. (2011): The impact of oral glutamine supplementation on the intestinal permeability and incidence of necrotizing enterocolitis/septicemia in premature neonates. J Matern Fetal Neonatal Med 24: 1294-1300.

28. Li N, Lewis P, Samuelson D, et al. (2004): Glutamine regulates Caco-2 cell tight junction proteins. Am J Physiol Gastrointest Liver Physiol 287: G726-733.

29. Khan J, Iiboshi Y, Cui L, et al. (1999): Alanyl-glutaminesupplemented parenteral nutrition increases luminal mucus gel and decreases permeability in the rat small intestine. JPEN J Parenter Enteral Nutr 23: 24-31.

30. Windmueller HG, Spaeth AE (1980): Respiratory fuels and nitrogen metabolism in vivo in small intestine of fed rats. Quantitative importance of glutamine, glutamate, and aspartate. J Biol Chem 255: 107-112.

31. Rhoads JM, Argenzio RA, Chen W, et al. (1997): L-glutamine stimulates intestinal cell proliferation and activates mitogenactivated protein kinases. Am J Physiol 272 (5 Pt 1): G943-953.

32. Scheppach W, Loges C, Bartram P, et al. (1994): Effect of free glutamine and alanyl-glutamine dipeptide on mucosal proliferation of the human ileum and colon. Gastroenterology 107: 429-434. 
33. Becker RM, Wu G, Galanko JA, et al. (2000): Reduced serum amino acid concentrations in infants with necrotizing enterocolitis. J Pediatr 137: 785-793.

34. Gribar SC, Sodhi CP, Richardson WM, et al. (2009): Reciprocal expression and signaling of TLR4 and TLR9 in the pathogenesis and treatment of necrotizing enterocolitis. J Immunol 182: 636-646.

35. Lin HC, Su BH, Chen AC, et al. (2005): Oral probiotics reduce the incidence and severity of necrotizing enterocolitis in very low birth weight infants. Pediatrics 115: 1-4.

36. Li W, Zheng XH, Zhou W, et al. (2011): Regulatory effects of glutamine on Toll-like receptor 4 in neonatal rats with necrotizing enterocolitis. Zhongguo Dang Dai Er Ke Za Zhi 13: 419423.

37. Poltorak A, He X, Smirnova I, et al. (1998): Defective LPS signaling in $\mathrm{C} 3 \mathrm{H} / \mathrm{HeJ}$ and $\mathrm{C} 57 \mathrm{BL} / 10 \mathrm{ScCr}$ mice: mutations in Tlr4 gene. Science 282: 2085-2088.

38. Hoshino K, Takeuchi O, Kawai T, et al. (1999): Cutting edge: Toll-like receptor 4 (TLR4)-deficient mice are hyporesponsive to lipopolysaccharide: evidence for TLR4 as the Lps gene product. J Immunol 162: 3749-3752.

39. Iwaki D, Mitsuzawa H, Murakami S, et al. (2002): The extracellular toll-like receptor 2 domain directly binds peptidoglycan derived from Staphylococcus aureus. J Biol Chem 277: 24315-24320. 